\title{
A Method of Shoulder Spica Cast Application In Shoulder Muscle Transfer Patients In Supine Position
}

\author{
Harsh R. Shah ${ }^{1, \odot ~ P r a w e s h i ~ S i n g h ~ B h a n d a r i ~}{ }^{2} \quad$ Mayur Goklani ${ }^{1} \quad$ Mukund R. Thatte ${ }^{1}$ \\ ${ }^{1}$ Department of Plastic Surgery, Bombay Hospital and Institute of \\ Address for correspondence Mukund R. Thatte, MCh Plastic \\ Medical Sciences, Mumbai, India \\ 2Department of Orthopaedics and Trauma Surgery, Tribhuvan \\ University Teaching Hospital, Nepal \\ Surgery, Room-6, $2^{\text {nd }}$ Floor, New Wing Building, Bombay Hospital \\ and Institute of Medical Sciences, Marine Lines, Mumbai 400020, \\ Maharashtra, India (e-mail: mthatte@gmail.com).
}

Indian J Plast Surg 2020;53:112-118

\begin{abstract}
Keywords

- birth brachial plexus palsy

- shoulder muscle transfer

- shoulder spica cast

Background Children with birth brachial plexus injury (BBPI) often require secondary surgery for the shoulder. The shoulder spica is necessary after shoulder muscle transfer surgery in babies with BBPI. However, its application can be difficult in the supine position under ane sthesia. The aut hors describe a simple and cost-effective method of applying the shoulder spica cast without changing the supine position under anesthesia.

Technique While still under anesthesia, the child is placed in a supine position and then elevated on the wooden bar. The POP roll is wrapped around in a cylindrical manner, starting from the level one inch above the anterior superior iliac spine. The contralateral shoulder is also incorporated into the cast.

Conclusion The spica application technique described comprises commonly available materials, such as a w ooden plank, pair of bols ters, plaster of Paris rolls, and dressing materials overcoming the need for customized apparatus or the operation table. The materials are easy to assemble and thereby applicable just about anywhere. The task also becomes less challenging for the anesthetic in the supine position. This technique is easily reproducible and cost-effective.
\end{abstract}

\section{Introduction}

Shoulder spica finds a common use after shoulder muscle transfer in babies with birth brachial plexus injury (BBPI). However, its application can be difficult in supine position. Many units here and abroad place the child in sitting position, while under anesthesia, to apply the spica. This is cumbersome and involves extra expertise of the anesthesiologist and a special table.

To overcome such problems, authors have come up with a simple technique using readily available simple devices to apply shoulder spica in children in supine position under anesthesia.

\section{Technique}

The equipment comprises the following:

1. A long, smoothly polished wooden plank of approximately 3 to 4 inches broad and approximately 5 to 6 feet long (-Fig. 1).

2. A pair of bolsters to withstand the weight of the patient (-Fig. 2).

The bar should be longer than the upper segment of the child, so as to support both head and buttocks simultaneously. The bolsters should be of adequate thickness to hold the wooden bar and thereby allow the patient to be raised high
DOI https://doi.org/

10.1055/s-0040-1708582

ISSN 0970-0358.
(C)2020 Association of Plastic Surgeons of India

\section{License terms}

()(1) $\Theta \circledast$ 
enough to pass cotton roll or plaster of Paris (POP) cast rolls through the gap ( - Fig. 3 ).

\section{Steps}

1. On completion of the muscle transfer procedure, a dressing is applied and the patient is made supine from lateral position while still being under anesthesia ( - Fig. 4). Position of the upper limb is maintained with shoulder in abduction above 90 degrees and in external rotation, elbow slightly flexed to hold the rotation more easily, and forearm supinated.

2. The anesthetist holds the head of the patient, surgical assistant secures the operated limb in the required position, and nurse secures the legs of the patient, while theater assistant places bolsters at head end, beyond the head of the child, and beneath the buttocks.

3. A smooth polished, adequately wide wooden bar is slid beneath the buttocks up to torso, slightly above head, in a way that the child is in midline and has one leg on either side of the bar (-Fig. 5).

4. The operating surgeon in the meanwhile prepares a POP slab and banyan type collar strips (simulating lapel of a coat) (-Fig. 6).

5. The operating surgeon then applies the spica cast in the usual manner, that is, a soft roll starting from the hand of the operated limb to the torso till the level of anterior superior iliac spine (ASIS), including the opposite shoulder ( - Fig. 7 ).

6. The soft roll layer is followed by application of the first folded slab over the operated limb, including the ipsilateral axilla. The plastic stem which is in the plaster roll is folded to additionally secure the angle and rotation at shoulder level ( - Fig. 8).

7. The two collar strips are then placed. These help to prevent the spica from slipping off the opposite shoulder. Wet plaster of Paris is then applied in a cylindrical manner (-Fig. 9), starting at a level one inch above ASIS. During this, one should ensure inclusion of the posterior ends of the collar strips in the cast.

8. The number of layers of the POP should be just adequate to form an effective strong cast. Soft cotton roll is then folded over its inferior end to protect the skin from the edge of the hard cast. There should be adequate space for the abdominal wall expansion ( $\mathbf{- F i g}$. 10). Finally, the surface of the cast is smoothened by gentle rubbing of the plastic cover of the roll.

9. After application of cast, the wooden bar can be removed by rocking gently toward the direction of the buttock; simultaneously, as the rod is coming out, the bolsters are removed ( - Fig. 11). In fact, removal of the rod ensures that the spica now has space for chest and abdominal motion.

10. The outline of the assembly for simplification is as in - Fig. 12.

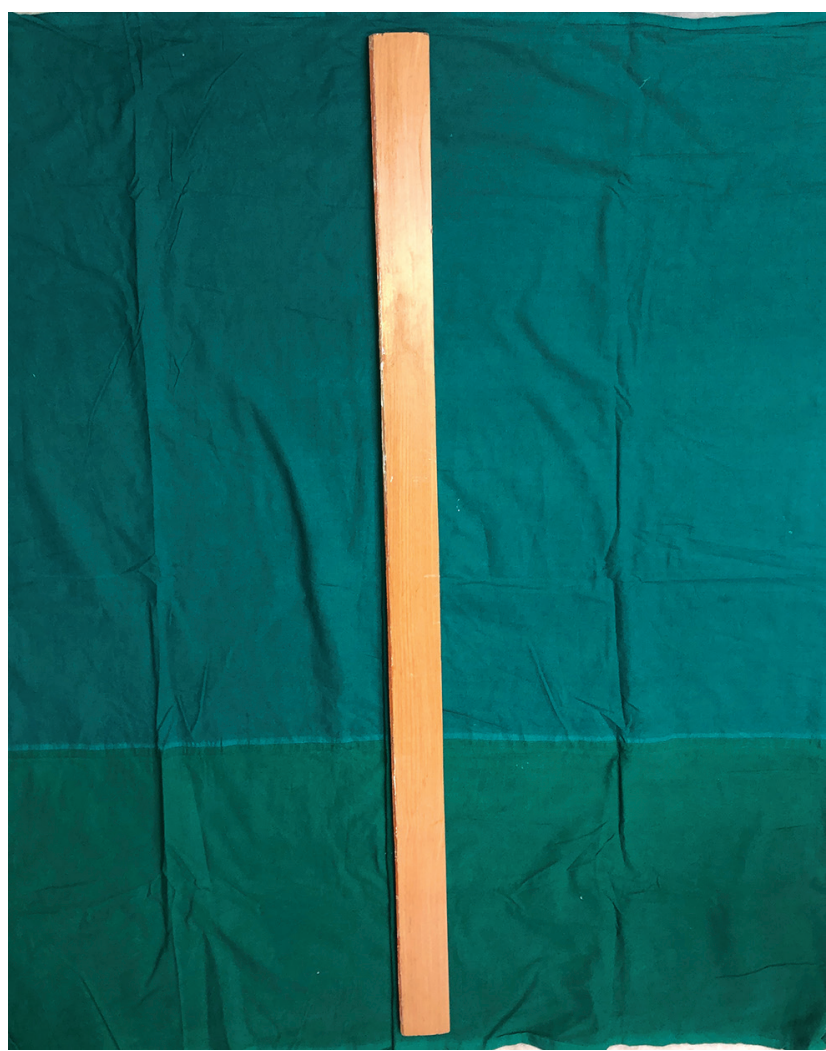

Fig. 1 A long, smoothly polished wooden plank.

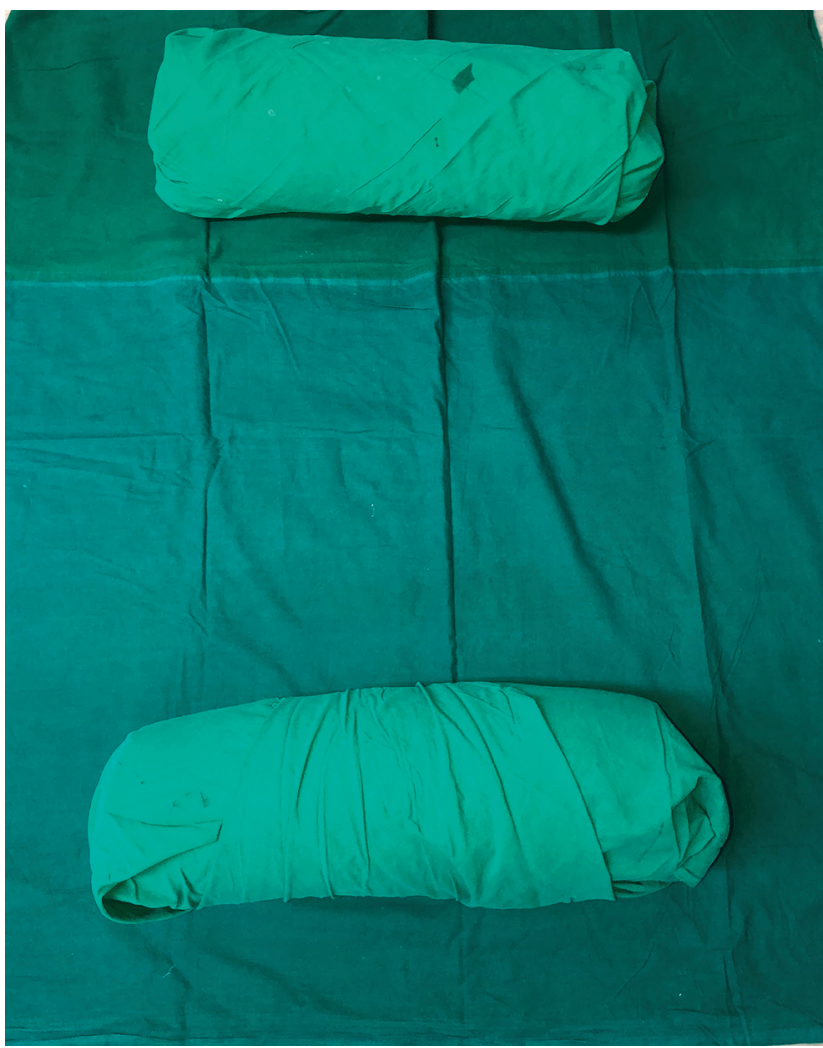

Fig. 2 A pair of bolsters. 


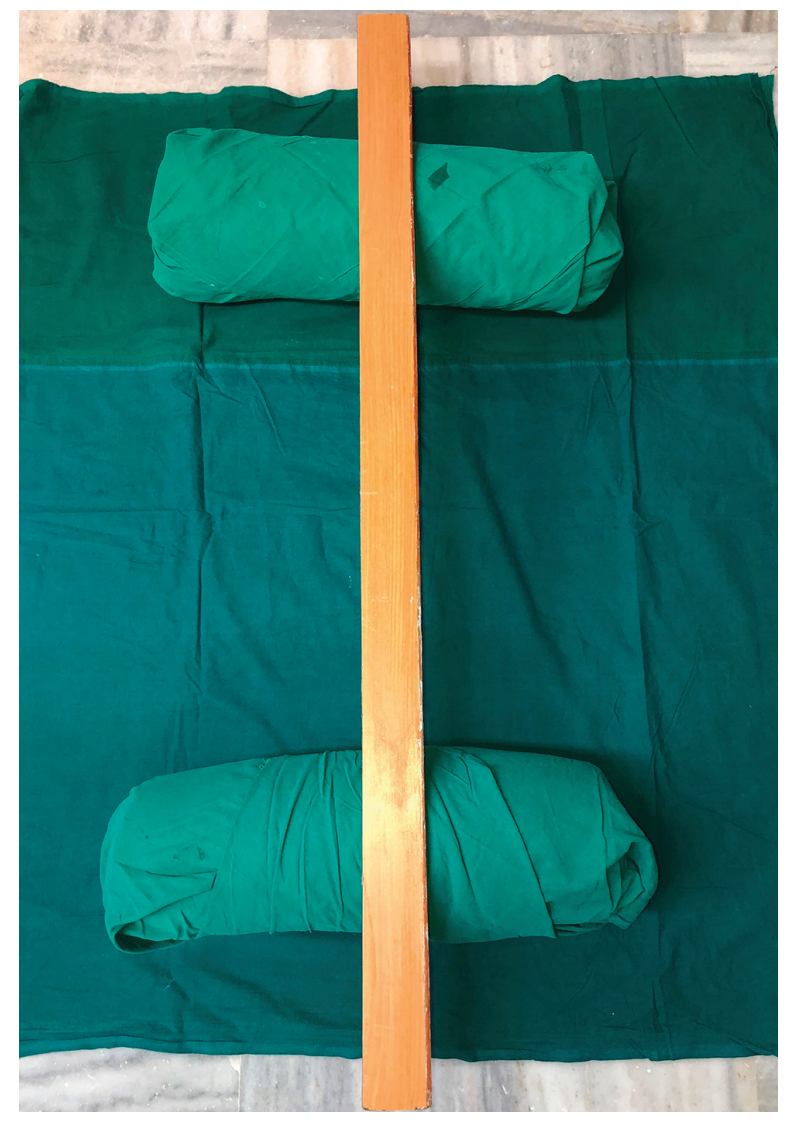

Fig. 3 The assembled equipment for the application procedure (the wooden plank and the bolsters).

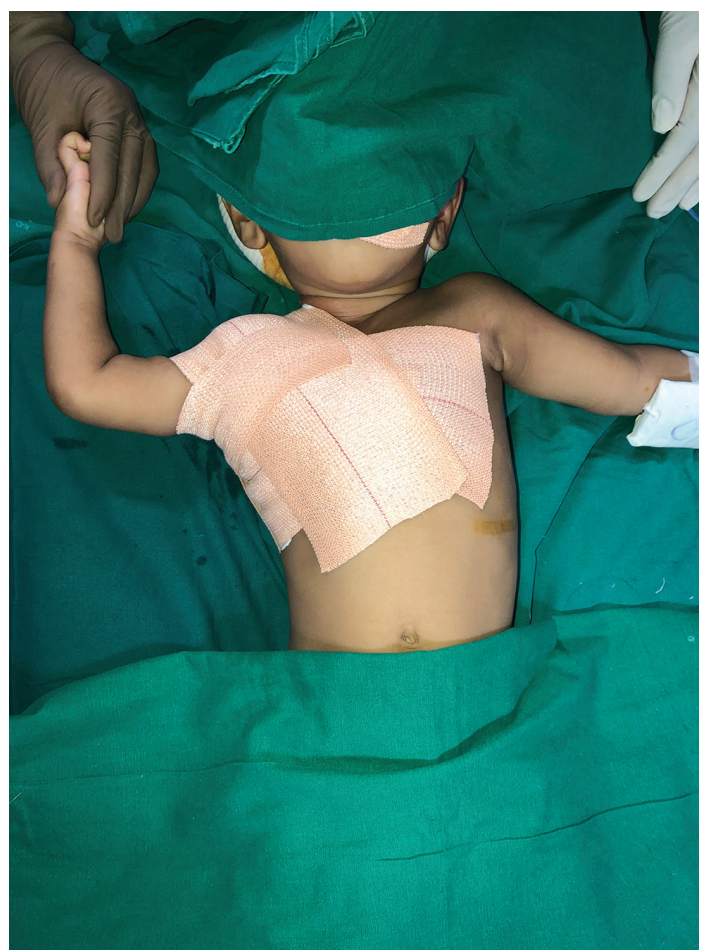

Fig. 4 Supine position of the patient after primary dressing of the operative site.

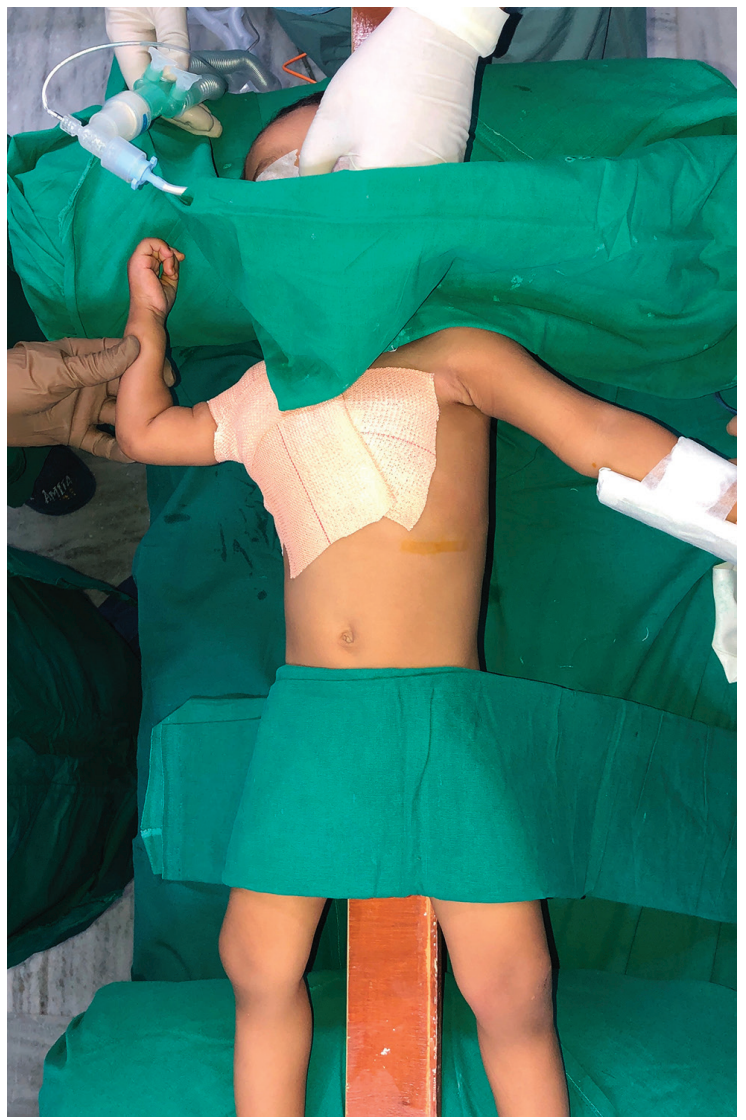

Fig. 5 Placement of the child in supine position over the assembly.

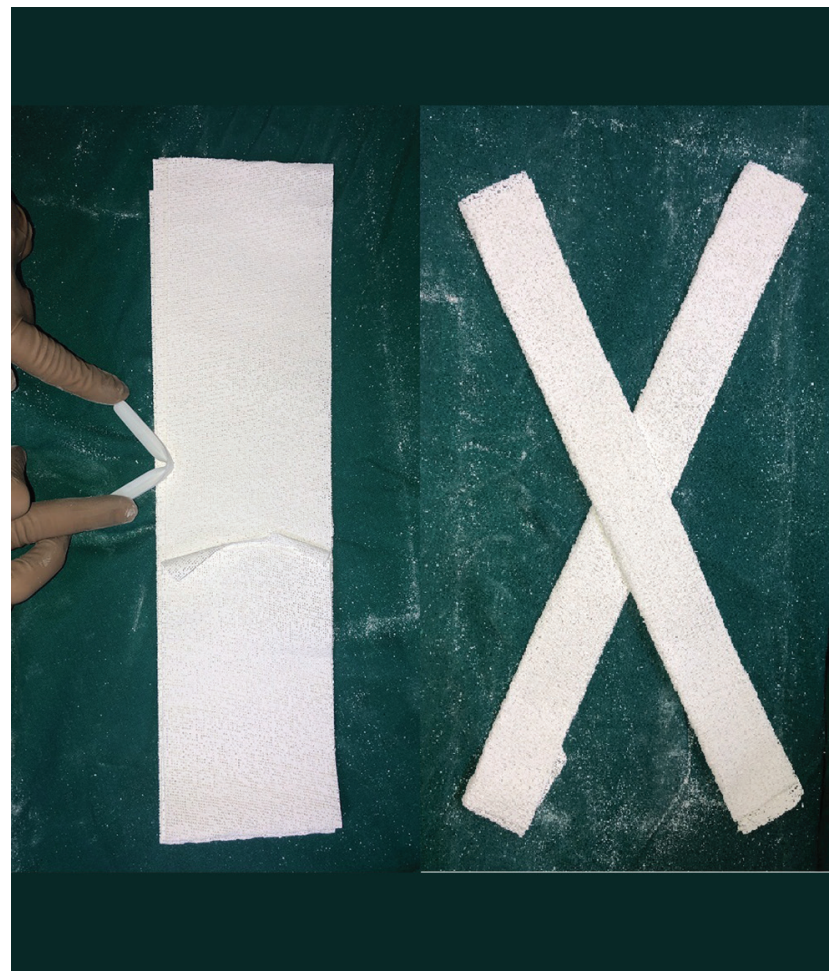

Fig. 6 Plaster of Paris slab and banyan type collar strips (simulating lapel of a coat). 


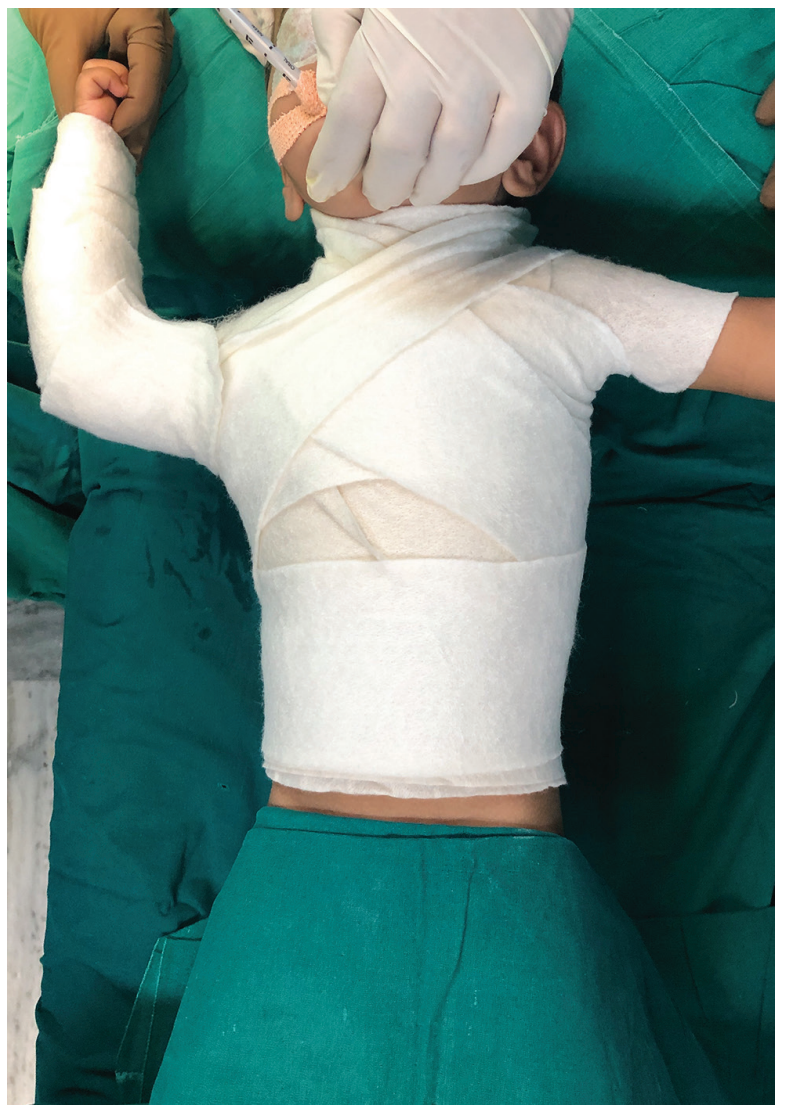

Fig. 7 Soft roll w rapped around the child, including the normal shoulder.

\section{Discussion}

This technique has been in use in our institute for application of shoulder spica for 21 years. We have in the past published our results of shoulder muscle transfers where this spica has been used. ${ }^{1}$ A standard wooden bar of breadth of around 3 to 4 inches could prove to be useful in most cases. A bigger size would be required for an overweight patient or adult patient. The devices described are easily available and can be locally assembled.

MacKinnon $^{2}$ had first described a different technique for the spica cast application to overcome the difficulties encountered in the conventional method wherein the assistant needs to hold the patient steady till the cast gets applied. He had devised a special apparatus made from the axle of a Ford car with an inverted U-shaped head. This technique required the need for this apparatus in very theater, which is less likely to happen.

$\mathrm{Chu}^{3}{ }^{3}$ in 1930, then simplified spica application by using the Hawley table and a sacral plate along with a pillow placed over an inverted basin. However, the described technique stands applicable for orthopedic oriented theaters; therefore, the suggested device may not be available in other theaters. We feel that our method is applicable just about anywhere without any special equipment.

Giele $^{4}$ in 2009, described a spica with the use of a thermoplastic material. The material is customized into a T-shaped splint, based on the measurements, and two rectangular pieces, of which one is used as shoulder strap for the ipsilateral shoulder and other as a supporting bar between the elbow and torso. On

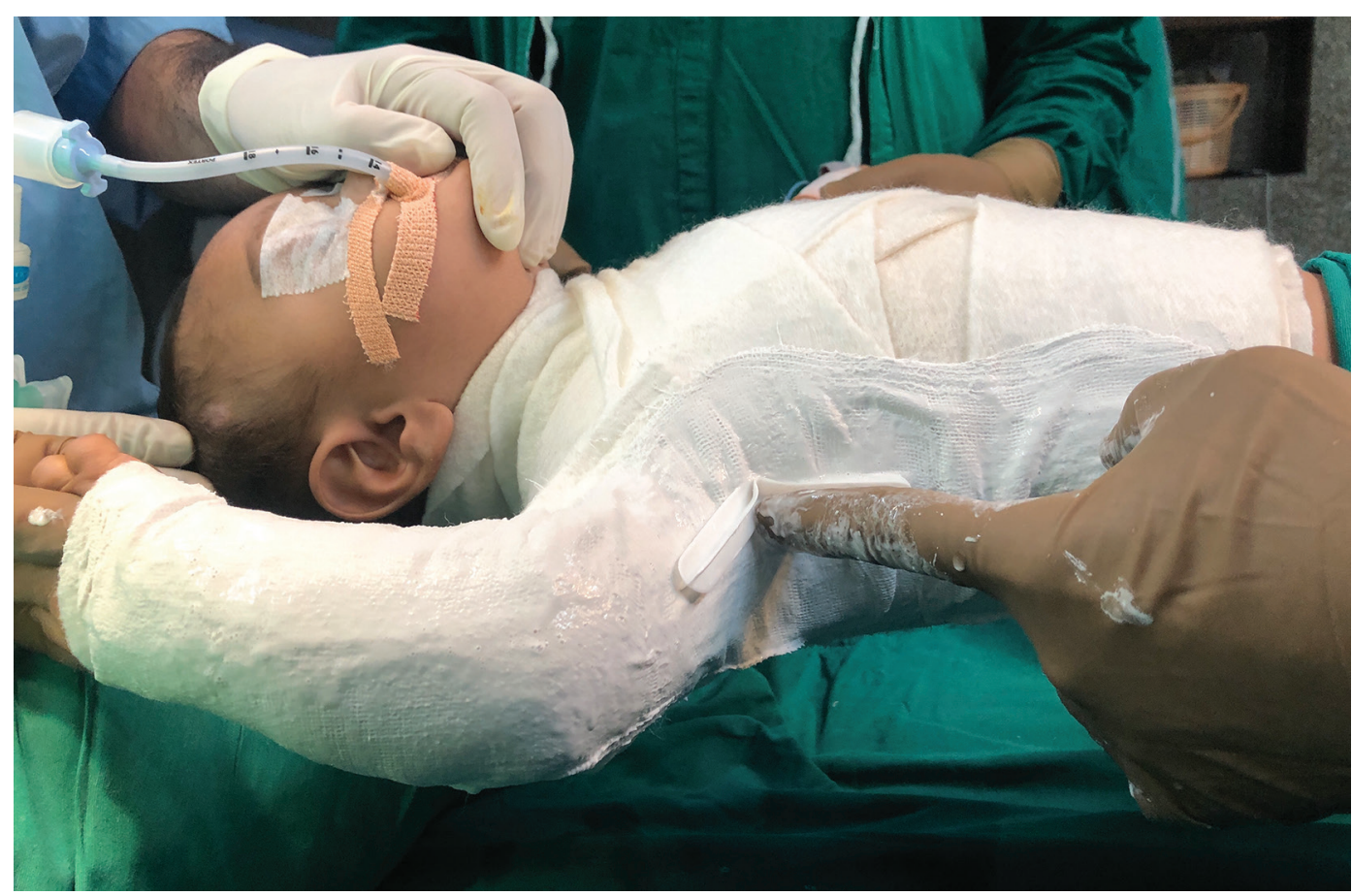

Fig. 8 The folded plastic stem being used to secure the angle and rotation at shoulder level. 


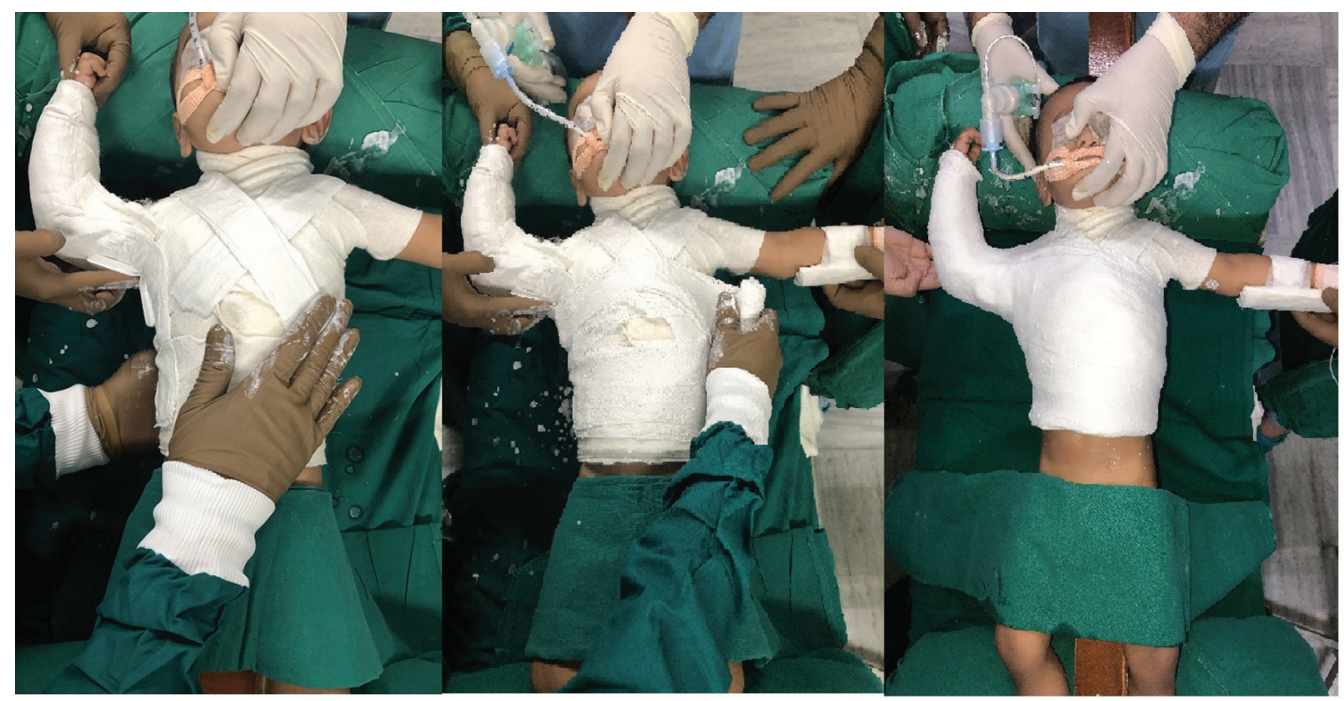

Fig. 9 (From left to right): Application of the two collar strips, application of the plaster of Paris in a cylindrical manner, Final appearance postapplication of plaster of Paris.

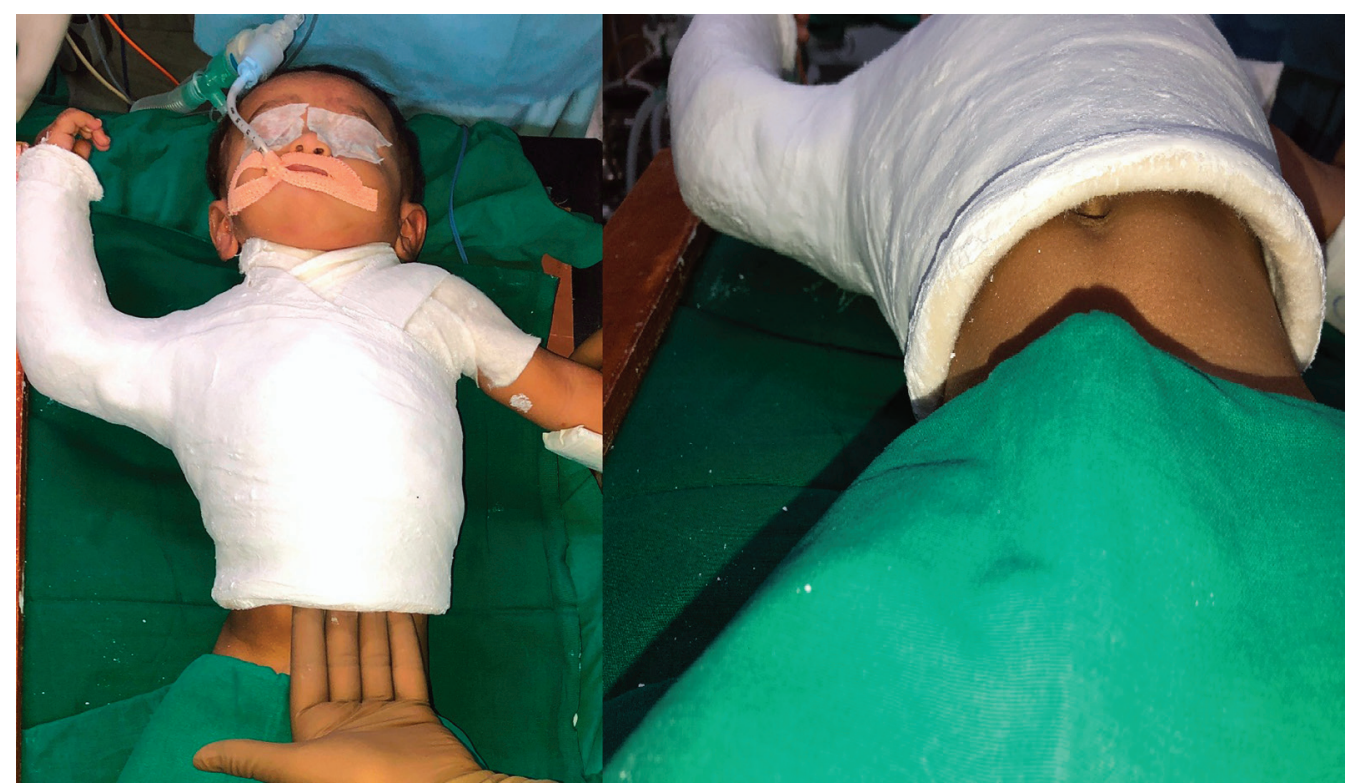

Fig. 10 Adequate space desired for the abdominal wall expansion, as viewed from above (left) and cross-sectional view (right).

the contrary, our technique involves two shoulder straps, one for each shoulder, which prevents slippage from the opposite side; also, we make use of the easily available plastic stick along the POP roll to give the position structural stability as observed in -Fig. 8. We feel our technique is simpler, more effective, and makes use of the material which is easy to procure and use.
Authors feel that this method is easily reproducible and cost-effective to apply shoulder spica.

\section{Source(s) of Support}

Nil. 


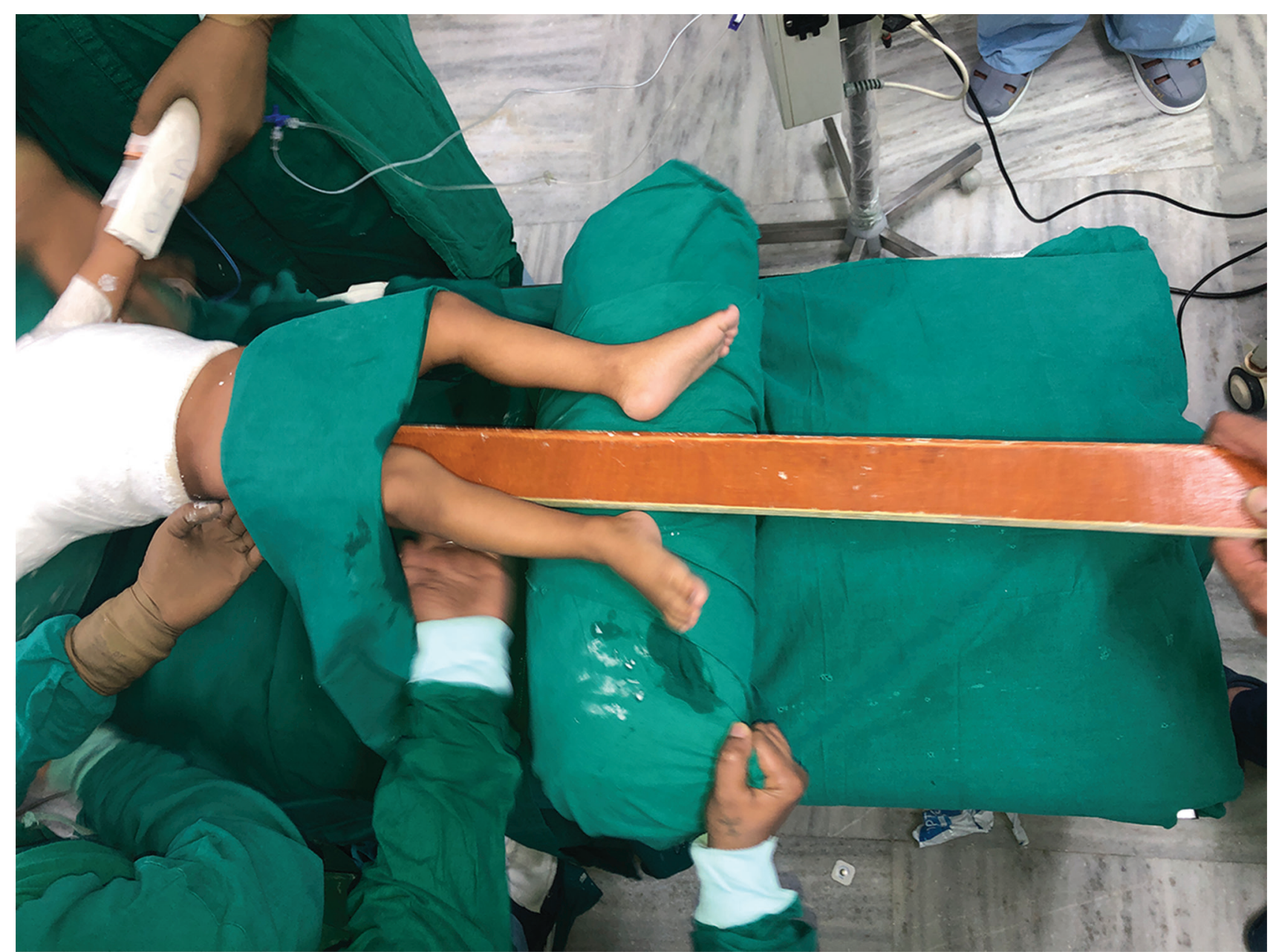

Fig. 11 Final removal of the assembly for shoulder spica application.

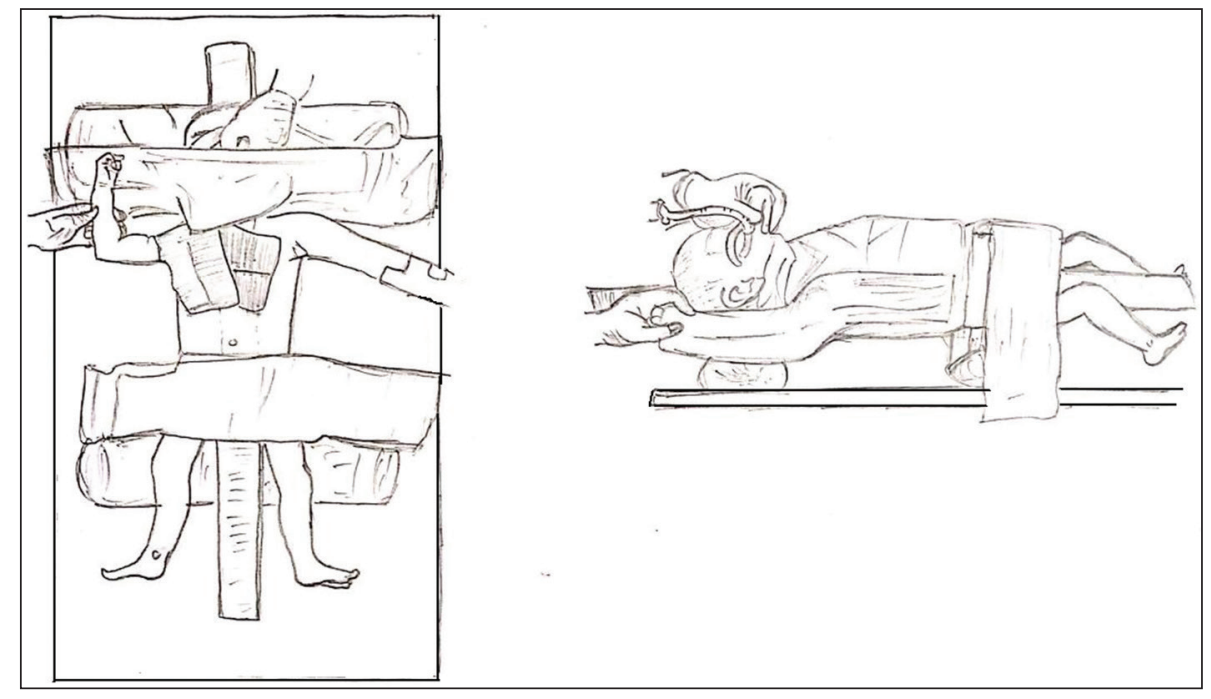

Fig. 12 Line diagram of the assembly. 


\section{Conflicting Interest}

Nil.

\section{References}

1 Thatte MR, Agashe MV, Rao A, Rathod CM, Mehta R. Clinical outcome of shoulder muscle transfer for shoulder deformities in obstetric brachial plexus palsy: A study of 150 cases. Indian J Plast Surg 2011;44(1):21-28

2 MacKinnon AP. The shoulder spica: a new apparatus. JBJS 1929;11:776-778
3 Chu LC. The shoulder spica a simple method of application. JBJS 1930;12(2):434-436

4 Giele H. A simple effective design for a thermoplastic shoulder spica following secondary surgery for obstetrical brachial plexus palsy. Hand Ther 2009;14:26-29 